\title{
Património e identidade. Reflexões sobre a intervenção patrimonial contemporânea nos castelos em Portugal
}

\begin{abstract}
Heritage and Identity. Reflexions about the contemporay heritage interventions on Potuguese castles.
\end{abstract}

\author{
Júlia Cristina Pereira de Faria \\ Doutoranda em Arquitectura na Universidade de Alcalá, Espanha
}

jcrispereira@sapo.pt

Recibido: 06/02/2015

Aceptado: 23/03/2015

\section{Resumo}

O conceito de património tem vindo a sofrer alterações para se adequar à multiplicidade de significados que o mesmo aporta para diferentes culturas, conduzindo a uma acumulação de património. Além disto, a crescente afluência de visitantes aos lugares patrimoniais foi interpretada como um benefício económico, tendo tido um impacto significativo nas intervenções patrimoniais, nomeadamente na progressiva musealização e adaptação à fruição pública. $\mathrm{O}$ património deixou, assim, de ser um processo de construção de identidade(s). Sendo que os castelos portugueses constituem um factor identitário para as comunidades onde se inserem, verificou-se, após uma análise da relação entre as intervenções patrimoniais contemporâneas nos castelos e as singularidades de cada contexto territorial, que estas não constituem um ponto de partida. Neste sentido, para colmatar esta problemática, deverá haver uma análise profunda do contexto local e uma maior participação da comunidade com vista à definição do património como um processo de construção de identidade(s).

Palavras-chave

Património, identidade, castelos portugueses, território, comunidade. 


\begin{abstract}
The concept of heritage has been transformed to face the different meanings which it has for different cultures, causing an accumulation of heritage. In addition to this, there was a large increase in the number of visits to heritage sites. This phenomenon was expected to generate economic benefits, having a significant impact on the heritage interventions, mainly in the increasing adaptation of heritage sites to museums and public fruition. The heritage is, then, no longer a process of construction of identity(ies). Despite Portuguese castles being a very significant part of their communities' identity, there was an evidence of a lack of adequacy between castles' heritage interventions purposes and the characteristics of the context in which castles are integrated. So, the singularities of each context were not taken into account. In this way, to solve this problem, a deep acknowledgement of how things are locally and the need for a higher community involvement should be taken into account, with the idea of defining heritage as a process of construction of identity(ies).
\end{abstract}

\title{
Keywords
}

Heritage, Identity, Portuguese castles, territory, community.

Referencia normalizada: FARIA, J. CRISTINA (2015): “Património e identidade. Reflexões sobre a intervenção patrimonial contemporânea nos castelos em Portugal". Arte y Ciudad. Revista de Investigación, no 7 (abril), págs. 167-194. Madrid. Grupo de Investigación Arte, Arquitectura y Comunicación en la Ciudad Contemporánea, Universidad Complutense de Madrid.

Sumário: 1.- Introdução. 2.- O conceito de património na contemporaneidade. 3.- A visita aos lugares patrimoniais como um fenómeno global. 4.- Os castelos no contexto português. 5.- Algumas considerações metodológicas e resultados. 6.- Notas conclusivas. 7.- Bibliografia.

\section{1.- Introdução}

O património, na actualidade, apresenta problemáticas emergentes e que devem merecer reflexão. Factores como a identidade, a expectativa económica subjacente às intervenções patrimoniais (com o objectivo de atrair mais visitantes) ou mesmo o progressivo afastamento dos cidadãos relativamente às decisões e gestão do património são fulcrais para se entender e questionar o papel do património na sociedade contemporânea. Desta forma, tornou-se 
pertinente efectuar um estudo ${ }^{1}$ para se verificar se estas problemáticas eram tidas em consideração nas intervenções patrimoniais mais recentes nos castelos portugueses, dado que os mesmos são um factor identitário significativo para as comunidades onde de inserem. Além desta questão, os castelos, pelo seu contexto histórico, apresentam uma grande atractividade para os que visitam as respectivas localidades.

Assim, primeiramente apresenta-se uma breve explicitação das problemáticas emergentes tanto do ponto de vista do conceito de património como do impacto económico que se espera obter com a afluência de visitantes a um determinado local, mediante uma intervenção patrimonial que suscite interesse, colocando em questão a sustentabilidade das intervenções patrimoniais relativamente aos diferentes contextos socioeconómicos.

Seguidamente, dado que cada contexto socioeconómico requer uma resposta diferenciada segundo as suas particularidades, é apresentada uma breve contextualização dos castelos portugueses relativamente ao território que os rodeia e também aos diferentes significados que os mesmos aportam consoante as diferentes regiões ou localidades.

Por fim, são delineadas algumas considerações que podem constituir um ponto de partida para colmatar os problemas verificados nas intervenções patrimoniais contemporâneas nos castelos portugueses, de forma a iniciar-se um novo caminho com vista a uma resposta efectiva às novas problemáticas do conceito de património.

\section{2.- O conceito de património na contemporaneidade}

O conceito de património, tal como se aplica actualmente, é essencialmente uma ideia construída das sociedades modernas e contemporâneas, conceito esse que foi separando gradualmente certos artefactos ou práticas culturais da sua contínua evolução e readaptação, ou simplesmente do seu fim ou abandono, relativamente ao quotidiano das sociedades. Constitui um processo que vai acontecendo à margem daquilo que sempre caracterizou a relação dos

\footnotetext{
${ }^{1}$ O presente estudo insere-se na Dissertação de Mestrado, da autora, com o título: O território, o castelo e a comunidade - reflexões sobre a intervenção patrimonial contemporânea nos castelos em Portugal, 2014, tese não publicada.
} 
indivíduos com o tempo e os lugares - um contínuo processo de criação de memória, baseado na selectividade de certos valores considerados pertinentes e identificativos para um determinado grupo, valores que seriam transmitidos à próxima geração.

Desta forma, poder-se-ia considerar que as sociedades convivem com uma grande multiplicidade de expressões patrimoniais, ou seja, coexistem diversos processos de criação de memória mesmo que esses não sejam reconhecidos pelo Estado ou pelas instituições autorizadas a identificar e a gerir o património, e não sendo, portanto, classificados.

Mesmo assim, a actualidade confronta-se com uma problemática - a acumulação de uma grande quantidade e diversidade de bens classificados (Aguiar, 2010; Custódio, 2010; Harrison, 2013). Para explicitar este fenómeno terá de avaliar-se diversas questões relacionadas com os paradigmas da globalização e do conceito de tempo para as sociedades contemporâneas. Augé afirma, a propósito da experiência do tempo na contemporaneidade, que:

A aceleração da história corresponde de facto a uma multiplicação de acontecimentos as mais das vezes não previstos pelos economistas, os historiadores ou os sociólogos. É a superabundância dos acontecimentos que constitui problema, e não tanto os horrores do século XX [...], nem a mutação dos esquemas intelectuais ou das convulsões políticas [...]. Esta superabundância [...] não pode ser plenamente apreciada senão tendo em conta por um lado a superabundância da nossa informação, e por outro lado interdependências inéditas daquilo a que alguns chamam hoje o sistema-mundo [...]. O que é novo não é que o mundo não tenha, ou tenha pouco, ou menos, sentido, é antes que experimentemos explícita e intensamente a necessidade quotidiana de [...] dar um sentido ao mundo [...]. Esta necessidade de dar um sentido ao presente, senão ao passado, é a contrapartida da superabundância de acontecimentos que corresponde a uma situação que poderíamos dizer de sobremodernidade, a fim de darmos conta da sua modalidade essencial: o excesso. (Augé 2005: 27-29).

A multiplicidade de acontecimentos simultâneos que ocorre na contemporaneidade alterou a forma como se entende o passado. $\mathrm{O}$ espaço temporal necessário à compreensão e reconhecimento de um dado artefacto como património alterou-se de forma paradigmática, sendo visível tanto na diversidade de bens classificados como no período necessário para que um bem seja passível para tal, que vem sendo gradualmente menor. 
Esta experiência do tempo, na qual as sociedades constantemente transcendem o presente para um futuro que está sempre iminente (Harrison, 2013) faz com que aquilo que se torna passado esteja em permanente risco de desaparecer, e cujo valor é incerto, ou difícil de definir, pois artefactos ou práticas que são quotidianas passam constantemente a pertencer a uma época passada, e sendo passíveis, portanto, de serem olhadas com uma espécie de nostalgia ou sentido de perda (Custódio, 2010).

Estes factores reflectem-se num esforço imenso, a nível global, de categorizar e classificar quase tudo, para que fique registado, mesmo aquilo que ainda não está considerado em risco (mas cuja perda é igualmente considerada iminente), cujo objectivo reside na sua própria classificação, de ordem arquivística. Este modelo de categorização remete para a tangibilidade daquilo que se pretende classificar, baseado em valores intrinsecamente ligados à materialidade, sendo que este conceito é resultado da institucionalização e da existência de discursos dominantes sobre o património, que atribuiu à materialidade do mesmo um papel representativo e significativo na definição de identidade nacional (Smith, 2006).

O conceito dominante de património caracteriza-se como algo que pertence a um dado momento histórico, e cujo papel na contemporaneidade reside ou residirá (a tendência arquivística dos bens classificados relaciona-se com uma possível interpretação por uma dada sociedade num futuro que não está definido) na sua interpretação. Esta é influenciada por fenómenos globais como a fruição pública nos lugares patrimoniais, as mudanças na economia e nos sistemas políticos, na mobilidade, etc. Poderá dizer-se que os valores ou significados sob os quais reside a interpretação do património como algo a posteriori entram em conflito, sob um dado ponto de vista, com outros paradigmas da contemporaneidade, relacionados com um aspecto particular: a identidade (e as suas diversas acepções).

Primeiramente deverá entender-se o que significa identidade. Os fenómenos de globalização transformaram e criaram novas e diversas formas de identidade, onde o individualismo e uma espécie de auto-identidade ganham uma nova expressão. Castells (2010) afirma que identidade constitui um processo de construção de significado baseado num atributo cultural, ou num conjunto de atributos culturais relacionados, aos quais é dada prioridade rela- 
tivamente a outras fontes de significado, sendo que para um actor individual ou mesmo colectivo, pode haver múltiplas identidades.

Neste sentido, pode dizer-se que a identidade não é algo inerente mas antes um processo de construção, através de símbolos, memória colectiva, artefactos da História, por exemplo, nos quais, como afirma Castells, "individuals, social groups and societies process these materials, and rearrange their meaning, according to social structure, and in their space/time framework" (2010: 7). Desta forma, se a identidade não é algo inerente, não poderá simplesmente ser representada pela materialidade dos artefactos ou práticas do passado; reside, pelo contrário, na contínua redefinição dos valores que o passado representa relativamente às necessidades sociais, políticas e culturais do presente (Smith, 2006).

Assim, dentro de um Estado-Nação e de uma sociedade civil que abstractamente partilha uma identidade, existem outras identidades simultâneas, não só referentes àquilo que se designa por multiculturalismo ${ }^{2}$ mas também por outro tipo de grupos ou comunidades que partilham outro tipo de valores, como o caso, por exemplo, das práticas religiosas que acontecem em Stonehenge, Inglaterra, na época do solstício de Inverno ou mesmo o papel da construção de uma identidade nacional nos países que resultaram da desintegração da União Soviética.

Harrison (2013), a propósito deste tema, refere que num mundo culturalmente diverso é impossível atribuir um conjunto de valores positivos a um único significado ou acepção de património. Os valores tradicionalmente associados ao património como valor cultural e científico, são, nas novas tendências da globalização, confrontados com realidades sociais e económicas, bem como com a política ambiental do desenvolvimento sustentável (Jokilehto, 2004).

Desta forma, os Estados-Nação foram perdendo progressivamente o controlo na selectividade e afirmação daquilo que representa a Nação como uma monocultura, geograficamente definida. $\mathrm{O}$ valor intrínseco atribuído então à

${ }^{2}$ Harrison (2013) refere que multiculturalismo foi um termo que ficou popular na década de 70 do século XX para descrever políticas governamentais com o objectivo de enfrentarem a problemática da existência de um grande número de diferentes grupos étnicos numa única Nação. 
materialidade do património como representativa de determinada identidade pode não ser reconhecido por outras formas de identidade. Isto significa que um mesmo artefacto pode representar múltiplos valores, desvinculado a materialidade dos valores tradicionalmente histórico-artísticos, como algo intrínseco. Assim, os artefactos podem ter significados diferentes e por vezes contraditórios, cujo papel na construção de identidade pode entender-se como tendo diferentes graus de importância.

Nesta ideia estão implícitas várias questões. Primeiramente, uma das questões remete para uma problemática anteriormente referida - a grande quantidade e diversidade de bens classificados, que está também associada à criação de memória colectiva, um dos aspectos relevantes na formação e afirmação de identidade.

Harrison (2013) refere então que se os objectos, lugares e práticas são preservados segundo critérios culturalmente determinados, significa que certos aspectos do património deixariam de ser relevantes e por isso passíveis de serem rejeitados. No entanto, contrariamente a esta ideia, novos bens patrimoniais (com novas categorias) têm sido classificados sem que se reveja a pertinência de bens classificados anteriormente. Harrison afirma ainda que a contemporaneidade enfrenta uma crise de acumulação de património que poderá enfraquecer o papel do mesmo na produção de memória colectiva, sobrecarregando as sociedades com diferentes vestígios de passados heterogéneos e afastando-as de um processo activo em formar memórias colectivas no presente.

Uma outra questão relaciona-se com os valores atribuídos ao passado: à forma como os mesmos são redefinidos no presente. Se os valores são mutáveis, poderá dizer-se que existe necessariamente uma interdependência entre a tangibilidade e a intangibilidade de um dado artefacto ou prática do passado. A propósito, Munjeri refere que:

cultural heritage should speak through the values that people give it and not the way round. Objects, collections, buildings, etc., become recognized as heritage when they express the value of society and so the tangible can only be understood and interpreted through the intangible. Society and values are thus intrincically linked (2004: 13).

A memória tem um papel muito significativo na forma como tais valores são redefinidos. Smith (2006) afirma que memória é um processo activo de 
recordar e esquecer, fundamental para a capacidade de compreender o mundo. Embora Smith refira que existem diversos tipos de memória e alerte para as diferentes interpretações que tal tópico pode gerar, foca a memória colectiva como memórias partilhadas entre um grupo, cujas legitimam interesses comuns da identidade do mesmo. Refere então que:

collective memory is passed on and shaped in the present by commemorative events, and is reshaped daily through transmission between members of the collective social or cultural group and the language they employ to frame and define those memories. (2006: 59)

Assim, o processo de memória colectiva e o que cada identidade entende como património emergem como uma nova problemática face a essa mesma crise de acumulação e aos efeitos da globalização de conceitos dominantes sobre a interpretação e conservação do que se designa tradicionalmente património.

\section{3.- A visita aos lugares patrimoniais como um fenómeno global.}

A definição tradicional e dominante de património encontra-se relacionada com a interpretação do mesmo e com o fenómeno global que a afluência pública aos lugares patrimoniais constitui na contemporaneidade.

A interpretação de um artefacto ou lugar patrimoniais como forma de transmitir uma mensagem que possibilite uma dada leitura ou mesmo uma experiência patrimonial foi sendo moldada por uma maior acessibilidade e interesse, por parte do público em geral, pelos lugares patrimoniais.

As mudanças económicas, sociais e de mobilidade a que se assistiu na segunda metade do século XX deram origem a um crescimento desse fenómeno, onde cada vez mais pessoas, com diferentes interesses, puderam ter acesso a actividades lúdicas, onde os lugares patrimoniais formam parte desse leque de actividades (Herbert, 1997).

A interpretação patrimonial, como refere Light (1997), implica uma série de técnicas de apresentação de forma a facilitar a aquisição de um conhecimento informal ${ }^{3}$ durante essas mesmas actividades lúdicas.

\footnotetext{
${ }^{3}$ No termo original informal education, que Light (1997) designa como sendo um conhecimento adquirido por auto-motivação, por voluntarismo e exploração, que pode acontecer durante uma visita a um lugar patrimonial.
} 
Refere também que a interpretação do património colocou uma ênfase cada vez maior no valor de entretenimento dado pelas instalações que possibilitam essa interpretação ${ }^{4}$.

Neste sentido, foram sendo acrescentados outros valores aos lugares patrimoniais de âmbito cultural e económico (Santos, 2012b), resultantes de uma audiência pública cada vez maior.

O património deixou então de ser simplesmente um símbolo da sociedade civil e parte de um instrumento educativo do Estado-Nação para constituir uma importante indústria (Harrison, 2013), onde prontamente se reconheceu a viabilidade do património à mesma (Santos, 2012b). Sendo que qualquer lugar tem, por princípio, um passado passível de ser explorado (Ashworth, 1995) como produto cultural, e relacionando com a crise de acumulação referida no ponto anterior, pode antever-se que essa indústria constitui na contemporaneidade um mercado muito significativo que coloca uma expectativa muito alta nos lugares patrimoniais como produtos com benefícios económicos e como factores de desenvolvimento, quer a macro ou a micro-escala. Harrison afirma a propósito que:

The state had a key role to play in the development of this new heritage industry, through the increasing forms of legislative control over heritage, which provided a platform for neoliberal policies that shifted away from the ideia of preservation for its own (or the public(s)) benefit and focused increasingly on the potential of heritage for local, regional and nation income generation. (2013: 83)

Esta questão tem implicações directas nas estratégias de conservação e preservação dos lugares patrimoniais desenvolvidas nas últimas décadas do século XX e que tende a persistir no século XXI. Assiste-se a uma produção cada vez maior de instrumentos legais que definem a forma como os lugares patrimoniais devem ser geridos e os parâmetros da interpretação, surgindo novos conceitos de intervenção como valorização, requalificação, revitalização, etc., ligados a uma nova condição do património - a rentabilidade e a expectativa centrada na atracção de visitantes. Smith (2006) considera que o património é associado a uma audiência de massas, cujo processo de partici-

${ }^{4}$ Deve referir-se que enquanto o entretenimento pode não ser um objectivo da interpretação, uma interpretação com qualidade pode permitir entretenimento de forma a manter o interesse de uma audiência (Light, 1997). 
pação no mesmo é reduzido a simples consumo, afirmando no entanto que esta ideia não significa que o património não é um recurso económico mas a redução do património como só ou largamente um produto ajuda a reforçar a ideia de que o património é algo que é passiva e acriticamente consumida. Esta ideia gerou uma interdependência entre os especialistas que constroem uma determinada mensagem e a forma como a mesma é interpretada pelos visitantes, ou seja, por actores passivos.

Para explicitar esta interdependência é necessário primeiramente entender o património como um produto contemporâneo criado no presente para servir as necessidades do mesmo (Ashworth, 1995) e que está sujeito a diferentes estratégias de marketing moldadas pela mudança do que se torna atractivo para o público ao longo do tempo.

Schouten (1997) afirma que para os visitantes o primeiro objectivo pode não ser a procura de evidência histórico-científica nos artefactos ou lugares patrimoniais - os visitantes procuram uma experiência, uma nova realidade baseada nos vestígios tangíveis do passado.

Esta noção de experiência, segundo Harrison (2013), é, em grande parte, consequência das mudanças que ocorreram nas décadas de 80 e 90 do século XX em termos tecnológicos e económicos, levando a uma alteração da promoção e venda de serviços para uma promoção e venda de experiências como parte de um novo modelo económico, levando à abertura de diversas tipologias de parques temáticos. Esta temática constitui uma esfera de mercado que influenciou a forma como os lugares patrimoniais são publicitados e consumidos na pós-modernidade.

A interpretação teve assim de assumir um compromisso entre uma mensagem factual e científica dos lugares patrimoniais e a possibilidade de uma experiência individual, baseada na presença no lugar patrimonial onde essa mesma experiência ocorre, bem como uma ligação de ordem sensorial ou emotiva, diferenciando-se da interpretação unidimensional (uma interpretação visual) como acontecia tradicionalmente nos museus, por exemplo (Schouten, 1997).

A experiência patrimonial como consumo, e consequentemente ligada ao entretenimento, foi também possível por uma revalorização do passado, num 
sentido nostálgico, pela sociedade contemporânea, num contexto em que a definição dominante de património se caracteriza como algo com valor intrínseco e que representa aspectos positivos de um dado momento histórico. Desta forma foi possível recriar um passado de acordo com as expectativas dos visitantes, baseado em aspectos que permitissem o entretenimento, numa conservação in situ. Esta concepção de património é partilhada reciprocamente pelo público e por especialistas, ou seja, os visitantes não irão valorizar lugares patrimoniais que não se enquadrem no conceito dominante (Smith, 2006), afastando gradualmente a noção de património como um processo activo na construção de identidade(s).

Um dos casos mais paradigmáticos e já referido por diversos autores (ver por exemplo Blake, 2002; Smith, 2006; Choay, 2006 e 2011; Harrison, 2013) é a Convenção do Património Mundial, Cultural e Natural, de 1972. Os lugares inscritos na lista de património mundial constituem uma marca (Harrison, 2013) usada na promoção de destinos internacionais, significando uma oportunidade que os Estados-Nação, bem como o comércio local e grupos de interesse, reconheceram para contribuir para a economia. Harrison (2013) aponta esta razão como um dos principais motivos para que o número de lugares classificados como património mundial tenha crescido de forma tão impressionante (e continue no século XXI) e os Estados tenham tido tanto interesse em ratificar a Convenção.

Os lugares classificados como património mundial criaram uma tensão entre a singularidade de cada lugar inscrito e simultaneamente a designação como um destino internacional, adaptado às necessidades dos visitantes e com uma mensagem globalmente aceite e entendida pelos mesmos. Desta forma, a grande acessibilidade a lugares patrimoniais originou uma redefinição dos visitantes como: "they are by definition culturally foreign to the heritage site in question and may be conceived as simply passing through" (Smith, 2006: 33).

Esta aparente desconexão com os lugares patrimoniais por parte de uma audiência de massas reforçou a ideia do entretenimento na experiência patrimonial e na forma como essa mensagem global é construída.

Assim, as técnicas de interpretação que constituíram a experiência patrimonial como objecto de marketing para atrair mais audiências foi tema de 
fortes críticas nas últimas décadas do século $\mathrm{XX}$, em três aspectos principais, que Herbert (1997) enuncia: um dos aspectos é referente à autenticidade, no sentido em que o processo de atrair visitantes pode distorcer e simplificar a veracidade histórico-científica do lugar patrimonial; o segundo motivo é a selecção da mensagem que deve ser interpretada, por parte de quem constrói a mesma, e o terceiro motivo é o impacto que uma grande afluência de visitantes a um determinado lugar pode originar no quotidiano das populações, principalmente em culturas não ocidentais: Locals are in danger of becoming part of spectacle [...] gazed upon by outsiders who know litlle or nothing about their culture and society [...] (1997: 11).

No entanto, as críticas anteriormente referidas têm sido confrontadas com novas abordagens nos estudos sobre o património (ver por exemplo Smith, 2006; Kidd, 2011; Harrison, 2013). Smith (2006) afirma que, em considerações tradicionais, se vê inevitavelmente o processo de comunicação ocorrendo numa direcção, em que os visitantes passivamente apreendem as mensagens construídas pelos profissionais ou mesmo por operadores turísticos, numa distinção entre produção e consumo.

Além disso, e como afirma Kidd (2011), o conceito de património tem adquirido diferentes significações ao longo dos anos mais recentes, numa enfâse cada vez menor na materialidade per se e maior sobre os vários significados que essa mesma materialidade pode manifestar e inspirar. Desta forma, a multiplicidade de identidades existentes possibilita leituras muito variadas e distintas sobre um mesmo lugar patrimonial, questionando-se a efectividade da compreensão da mensagem seleccionada que deve ser interpretada.

Estes estudos mais recentes têm introduzindo mudanças no conceito de autenticidade, relativamente à forma como tradicionalmente o mesmo tem sido utilizado, para algo ligado ao processo de criação de memória e aos aspectos sensoriais que isso pressupõe, que Smith (2006) define como emotional authenticity, tal como Kidd: [...] "our relationship with the authentic emerges as interpretive, negotiated and personal, as far from absolute and measurable" (2011: 25). Assim, uma experiência patrimonial torna-se autêntica se o visitante, para si mesmo, a validar como tal, e daí a ideia de experiência como um envolvimento activo do visitante com o lugar patrimonial, contrariamente ao conceito de audiências passivas ou de massas: 
the intricacy of the web of associations and value that can overlay any heritage site, object or place is often obscured not only by the nature of the $\mathrm{AHD}^{5}$, but also specifically by the dismissal of heritage performativity and experience as a [...] commodity. (Smith, 2006: 73)

Desta forma, são colocadas novas questões à gestão dos lugares patrimoniais e à sua interdependência com a fruição pública na contemporaneidade, nomeadamente no que se refere à promoção e consequente saturação de certos lugares com visitantes, além do contexto da crise financeira e da expectativa que se colocou (e se coloca) nos lugares patrimoniais como produtos com benefícios económicos.

Tem havido, assim, um foco cada vez maior nas oportunidades que uma participação activa das comunidades no processo de decisão pode significar relativamente às práticas de conservação, defendendo-se uma mediação entre o conhecimento dos especialistas e as opiniões das comunidades e outros agentes directamente envolvidos nas questões da gestão e conservação do património. Duarte (2010) afirma que o património dificilmente servirá a noção de identidade e continuidade se se visar apenas nas práticas e expressões culturais em extinção, que perderam o seu significado e são mantidas unicamente através de medidas artificiais e intervenções burocráticas. Defende também que, em alternativa ao sentimento de perda, o principal propósito para defender o património deveria residir nas dinâmicas sociais contemporâneas, sendo apenas desta forma que o património pode contribuir para o desenvolvimento sustentável das comunidades. Folgado (2010) reconhece que a perspectiva económica constitui ainda uma importante estratégia para o património mas dos novos desafios colocados ao mesmo poderá emergir um património mais plural e próximo das populações, em que se perspectiva o seu envolvimento na gestão e perpetuação dos valores de uma sociedade complexa e igualmente plural.

Estas novas acepções são igualmente partilhadas, por exemplo, por Smith (2006), por Altenburg (2010) e por Harrison (2013). Harrison defende um modelo chamado dialogical heritage, que resulta de uma maior interacção entre diferentes grupos da sociedade no processo do poder de decisão na identificação,

${ }^{5}$ Authorized Heritage Discourse. 
classificação e gestão do património, que responde ao progressivo afastamento de cidadãos comuns em tais decisões e suas consequentes implicações:

Thinking of heritage not as a set of tangible things, nor as intangible expressions and pratices, but instead as relational and emergent in the dialogue between people, objects, places and pratices also has implications for how we think about and manage heritage in the future. It implies notions of obligation, responsability, care, curation and ethics, but also suggets that conservation is as much a social process as it is a physical or technical one [...]. (2013: 226)

Como pode ser observado, não se trata de anular todo o conhecimento até agora desenvolvido, mas antes questionar diferentes abordagens como resposta às críticas que têm surgido na gestão e classificação do património.

Estas novas abordagens colocam também diversos desafios à promoção dos lugares patrimoniais e que devem ser tidos em consideração.

Estudos mais recentes (ver por exemplo Stevens, 1997; Soifer, 2009; Cardona, 2009; Belyaev, 2010) revelam uma preocupação em responder a uma audiência de massas, numa perspectiva relacionada com a contribuição da afluência de visitantes num determinado lugar para o desenvolvimento local e a sua adaptação às particularidades do mesmo. Foca-se também a importância das organizações e comunidades locais no reconhecimento do que pode ser potenciado a nível local e no envolvimento directo das mesmas na contribuição para a economia local.

\section{4.- Os castelos no contexto portugués.}

Após a explicitação anterior dos desafios que actualmente são colocados à classificação e gestão do património, apresenta-se um enquadramento dos castelos no contexto português. Constituindo os mesmos um factor identitário muito relevante, é necessário observar de que forma o conceito de identidade, aplicado a este caso particular, poderá influenciar a intervenção patrimonial nestas estruturas mediante os diferentes contextos socioeconómicos existentes.

A arquitectura militar medieval em Portugal está associada a uma estratégia nacional de definição de fronteiras e de povoamento do território, além do seu controlo em termos administrativos e económicos. Assume, desta forma, uma importância no território em termos de imagem e impacto na paisagem, 
bem como na memória colectiva. São, portanto, elementos de referência geográfica, urbana e histórica nas localidades onde se encontram.

Neste sentido, torna-se pertinente uma análise da relação dos castelos com a construção do território para se entender determinados valores a eles associados e quais as implicações nas intervenções patrimoniais destas estruturas defensivas.

Como refere Santos, o estudo de uma estrutura defensiva, como por exemplo os castelos, não se limita aos aspectos morfo-tipológicos ou geoestratégicos:

para compreender o edifício estudado, ainda que os aspectos arquitectónicos sejam primordiais, é necessário incluir as considerações arqueológicas, artísticas, políticas, tecnológicas, económicas, geográficas, demográficas, etc. Por esta razão a castelologia compõe-se simultaneamente de partes da historiografia da arquitectura, da arte, militar, política, económica, da tecnologia, da sociologia, da religião, da geografia e de muitas outras especialidades com diferentes objectos de estudo [...] que há que conciliar. (2012a: 107)

Do ponto de vista da intervenção patrimonial nos castelos, estas considerações são relevantes sobretudo tendo em vista as novas problemáticas relativas ao património, tanto na multidimensionalidade da sua definição como no entendimento de intervenção patrimonial. Desta forma, a compreensão do contexto paisagístico no qual um castelo se insere poderá dar premissas para a elaboração de uma intervenção patrimonial que consiga responder às particularidades desse mesmo contexto, pois nas várias regiões portuguesas os castelos tiveram um papel distinto na construção do território (Marques, 1988), e poderá questionar-se se daí poderão advir ou não, na contemporaneidade, diferentes valores associados aos castelos, nas diferentes regiões, e se haverá implicações que devem ser tidas em consideração numa intervenção patrimonial nessas estruturas defensivas.

Assiste-se, então em Portugal, a diferentes estratégias de ocupação do território, no contexto da Reconquista e na definição das fronteiras bem como na gestão do reino sob o controlo régio. Desta forma, o território conquistado que definirá sensivelmente as fronteiras actuais em 1249, com a conquista do Algarve (Andrade, 2001), apresentava diferentes contextos, sobretudo entre o Norte e o Sul. A propósito, Orlando Ribeiro refere que: 
Ao norte do Tejo ficava a terra dos Lusitanos e ao norte do Douro a dos Calaios, aparentados com eles na rudeza e na bravura com que resistiram às armas romanas. Os povos do Sul eram mais polidos. Aí se encontram mais frequentes vestígios de relações com os navegadores do Mediterrâneo, Fenícios, Gregos, Cartagineses e com a [...] civilização indígena de Tartessos [...]. Na mesma área terão assentes as principais cidades e estabelecimentos romanos, visigóticos e árabes. (1998: 137)

Esta aparente dicotomia entre diferentes formas de vida e inevitavelmente diferentes paisagens associadas tem uma importância destacada nas diferentes estratégias utilizadas por parte do então reino português, onde os castelos são também reflexo dessas acções, em que se verifica, por exemplo, materiais de construção tão distintos como por exemplo a taipa, como no caso do castelo de Paderne, a alvenaria de tijolo, como no caso do castelo de Viana do Alentejo, o granito, como nos casos dos castelos de Póvoa de Lanhoso e Guimarães ou até a utilização de arenito, como no caso do castelo de Silves.

Os castelos são já elementos presentes na paisagem quando se inicia a Reconquista para além das fronteiras do Condado Portucalense, autonomizado em 1096 (Andrade, 2001).

O domínio árabe, em Portugal, que se divide em cinco fases - fase inicial (711), califal (929), das taifas (1031), almorávida (1085) e almóada (1157) - apresentava uma organização do território distinta daquela que se verificava no Norte de Portugal, introduzindo, por influência oriental, diferenças substanciais às estruturas defensivas, tanto na sua componente tipológica como na crescente importância estratégica da estrutura defensiva (Nunes, 1988) - uma parte significativa dos castelos existentes em Portugal têm origem árabe, embora, pela maior permanência dos árabes no sul, os castelos dessa região apresentem uma maior influência árabe. Assim, além da conquista do território a sul e do consequente povoamento, as fronteiras a norte e a leste teriam de ser igualmente asseguradas pela ameaça dos reinos cristãos vizinhos. As estratégias utilizadas, perante diferentes contextos não passavam então exclusivamente por questões militares, como Andrade (2001) refere: as mesmas teriam de ser acompanhadas por acções que permitissem a autoridade régia ao mesmo tempo que respondessem a diferentes contextos e paisagens. Desta forma, Andrade afirma que no sul pretendiase uma substituição da ocupação muçulmana, sobretudo no enfraquecimento dos dinâmicos centros urbanos e na tentativa da adaptação dos cristãos, vindos do Norte, a formas de ocupação do território muito diferentes. Na zona beirã era 
não só necessário defender e afirmar a fronteira perante o interesse leonês mas também reforçar a autoridade régia perante comunidades com um acentuado carácter de comunitarismo devido ao isolamento e às dificuldades geradas pelas condições adversas da paisagem. Além disto, no noroeste havia que assegurar o controlo sobre o avanço galelo e ao mesmo tempo gerir os interesses senhoriais que caracterizavam a região. Neste contexto, perante diferentes realidades, os privilégios concedidos às povoações apresentavam singularidades. Estes privilégios eram atribuídos através das cartas de foral, redigidas não só para fomentar o povoamento mas responder também às características das comunidades e das particularidades das suas tradições anteriores (Andrade, 2001).

Desta forma, os castelos, ao mesmo tempo que definem uma área de defesa, juntamente com outros castelos de uma mesma linha estratégica, defendiam também a população dessa mesma área, cuja importância militar vai gerar uma povoação no seu entorno (Nunes, 1988) devido então aos privilégios que tentam fixar a povoação e que lhes atribui também um enquadramento jurídicoadministrativo estável (Marques, 1988). Alguns castelos irão ser consequentemente abandonados pela sua importância militar secundária, sobretudo se não deram origem a uma povoação (Nunes, 1988). Esta questão poderá ter implicações no que toca à intervenção patrimonial, no sentido em que se deve entender os valores associados a estes castelos de enquadramento isolado, bem como a relação existente entre povoações próximas ou inseridas numa linha estratégica, ou mesmo, no caso de existirem paralelismos entre linhas de defesa portuguesas e espanholas, a relação entre essas mesmas povoações dos diferentes países.

As diferentes estratégias de povoamento deram origem a regiões distintas, onde é possível observar ainda na actualidade, nas fronteiras raianas, um povoamento bastante menos denso do que nas regiões do litoral, por exemplo. A administração do reino e a rede de concelhos e sedes de poder corresponde, em linhas gerais, à administração concelhia actual, onde geralmente os castelos existentes com povoação são sedes de concelho ou foram em períodos anteriores próximos. Outro exemplo que deriva dessas estratégias são as feiras e feiras francas, instituídas pelo poder régio, sobretudo no período medieval, onde uma parte substancial das mesmas ainda existe com a regularidade do início da sua criação - este aspecto é claramente um legado patrimonial mas não institucionalizado/classificado e não entendido como património no sentido tradicional do termo. 
As cartas de foral constituem motivo frequente para celebrações nas comunidades às quais foram atribuídas, e que se poderá enquadrar como um acto de comemoração, ou seja, uma acto enquadrado na construção de memória colectiva. Ainda relativamente aos aspectos intangíveis, os castelos, no contexto português, são por vezes associados aos mouros, uma expressão de cariz popular, onde transparece frequentemente um carácter depreciativo. A propósito, Barros, no seu estudo sobre a permanência muçulmana em Portugal após a Reconquista, refere o seguinte:

O mouro, enquanto realidade histórica que, teoricamente, desaparece da tessitura social portuguesa em 1497, é recuperado pela imagética popular em múltiplas acepções, que vão desde os provérbios às lendas. [...] Esta recuperação popular de um tempo não domesticado pela história parece estender-se numa longa duração, como se continuasse a representar uma alternativa camponesa a todos os poderes entretanto estabelecidos. O refúgio neste imaginário apreciase, ainda hoje, nas zonas rurais, na imputação de qualquer vestígio material mais vetusto a esse quimérico tempo dos mouros. (2007: 18)

Barros refere ainda que nos textos e crónicas que descrevem o período de conquistas do território de ocupação árabe, os mouros são frequentemente descritos como totalmente dizimados e é reforçada a superioridade cristã, onde os árabes capturados e mantidos em cativeiro se remetem para um estatuto de inferioridade, estatuto esse que será expresso na redacção das cartas de foral no que respeita à definição do estatuto de mouro ou mouro forro, ou ainda outras designações, consoante cada tipologia de carta de foral. Desta forma, a integração do mouro no território nacional apresenta diferenças no que diz respeito às regiões do Norte e Sul, como Barros (2007: 614) afirma:

O Norte rural assimila, mesmo em termos religiosos. O Sul urbano assenta na diferenciação. As cidades redimem os mouros forros ao mesmo tempo que os controlam, concentrando os grupos organizados e legalmente reconhecidos: as comunas.

Esta conclusão poderá contribuir para se entender a imagética popular relacionada com os castelos no que se refere às diferentes regiões, onde o período de permanência árabe é claramente distinto, embora não se tenham encontrado estudos que o demonstrem de alguma forma.

Este aspecto tem relevância, no sentido em que a associação dos castelos aos mouros pode ou não influenciar a opinião sobre uma determinada inter- 
venção patrimonial num dado castelo por parte da comunidade onde essa imagética popular esteja presente, não directamente com a intervenção per se mas com a necessidade e utilidade da mesma num legado ao qual os valores atribuídos por parte das comunidades possam diferir daqueles que estão subjacentes à sua classificação e gestão.

Sendo que os aspectos tangíveis e intangíveis não podem ser dissociados daquilo que define o património, como afirma Munjeri (2004), algumas questões abordadas anteriormente deveriam ser analisadas para a compreensão dos castelos e da paisagem que integram.

\section{Algumas considerações metodológicas e resultados.}

Dada a grande quantidade de castelos existentes em Portugal, não foi possível efectuar um estudo exaustivo de todas as intervenções patrimoniais contemporâneas nos castelos. Optou-se então por uma selecção através da definição de um enquadramento temporal, geográfico e as intervenções que apresentassem uma nova abordagem quanto ao conceito e programa, mediante as características introduzidas na última década do século $X X$ no que toca às intervenções nos castelos portugueses. Utilizou-se, desta forma, uma metodologia de âmbito qualitativo, através de estudos de caso, segundo Yin (2003).

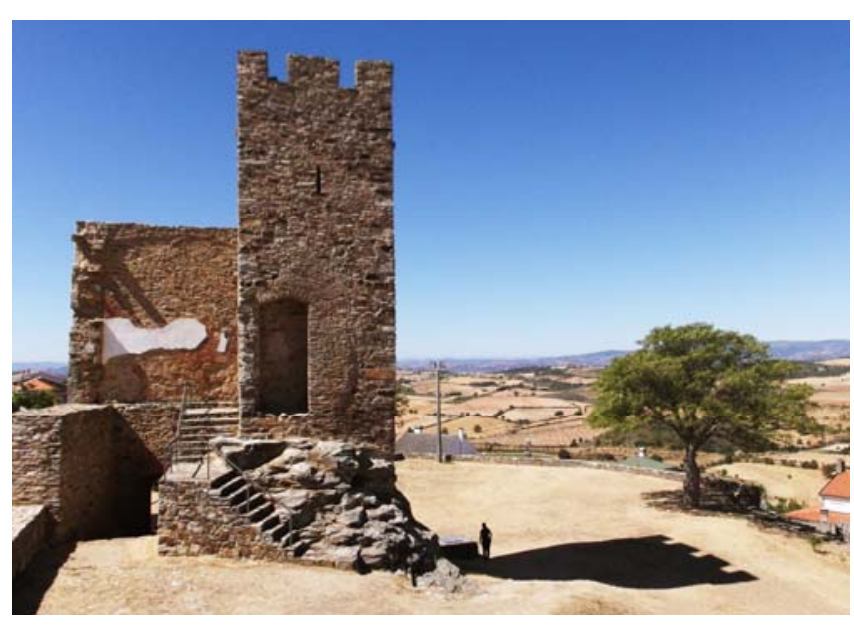

Figura 1. Castelo de Mogadouro: torre de menagem. Mogadouro, distrito de Bragança, região de Trás-osMontes e Alto Douro, 2013. Fotografia da autora.
Desta selecção resultaram então sete estudos de caso, nomeadamente o castelo de Mogadouro (1), na região de Trás-os-Montes e Alto Douro, os castelos de Trancoso (2) e de Celorico da Beira, na região da Beira Alta, o castelo de Castelo Novo, na região da Beira Baixa, o castelo de Amieira do Tejo, na região do Alto Alentejo e, por fim, o castelo de Silves, na região do Algarve. 


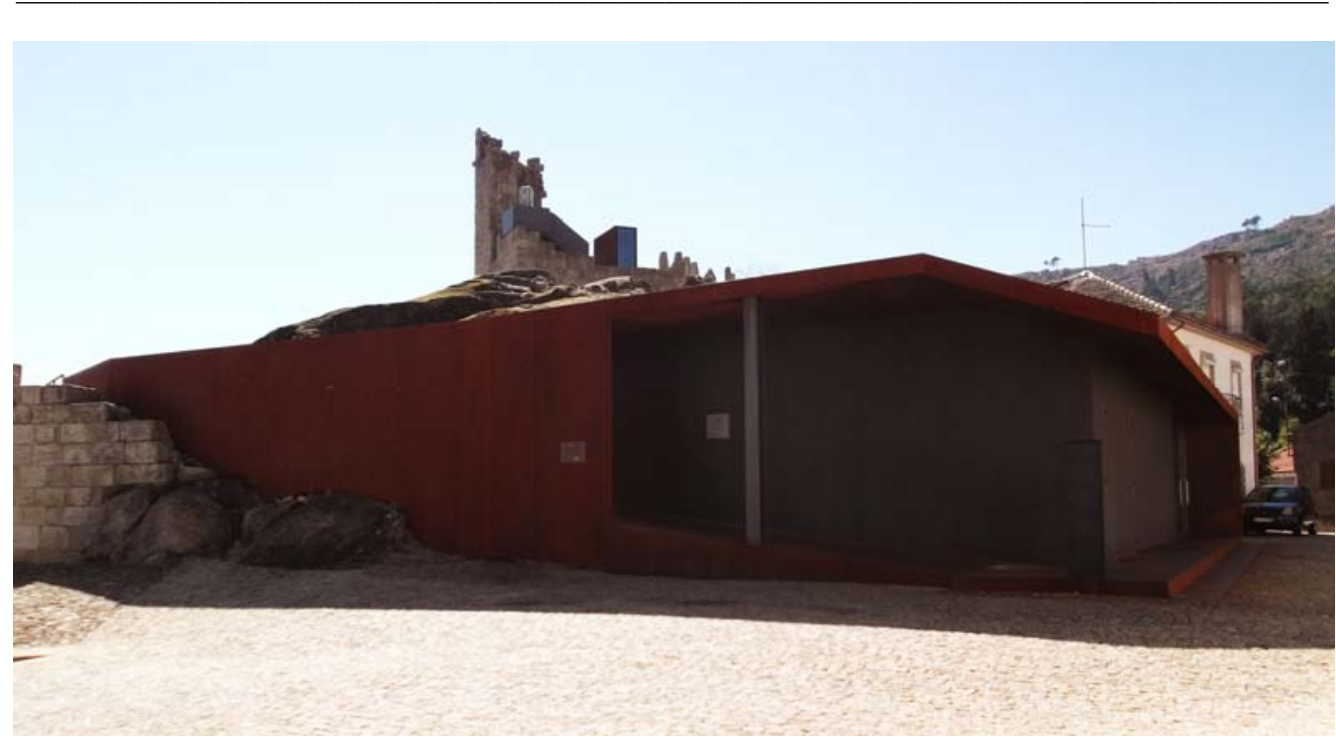

Figura 2. Castelo de Castelo Novo: espaço de recepção ao público resultante da intervenção patrimonial. Castelo Novo, distrito de Castelo Branco, região da Beira Baixa, 2013. Fotografia da autora.

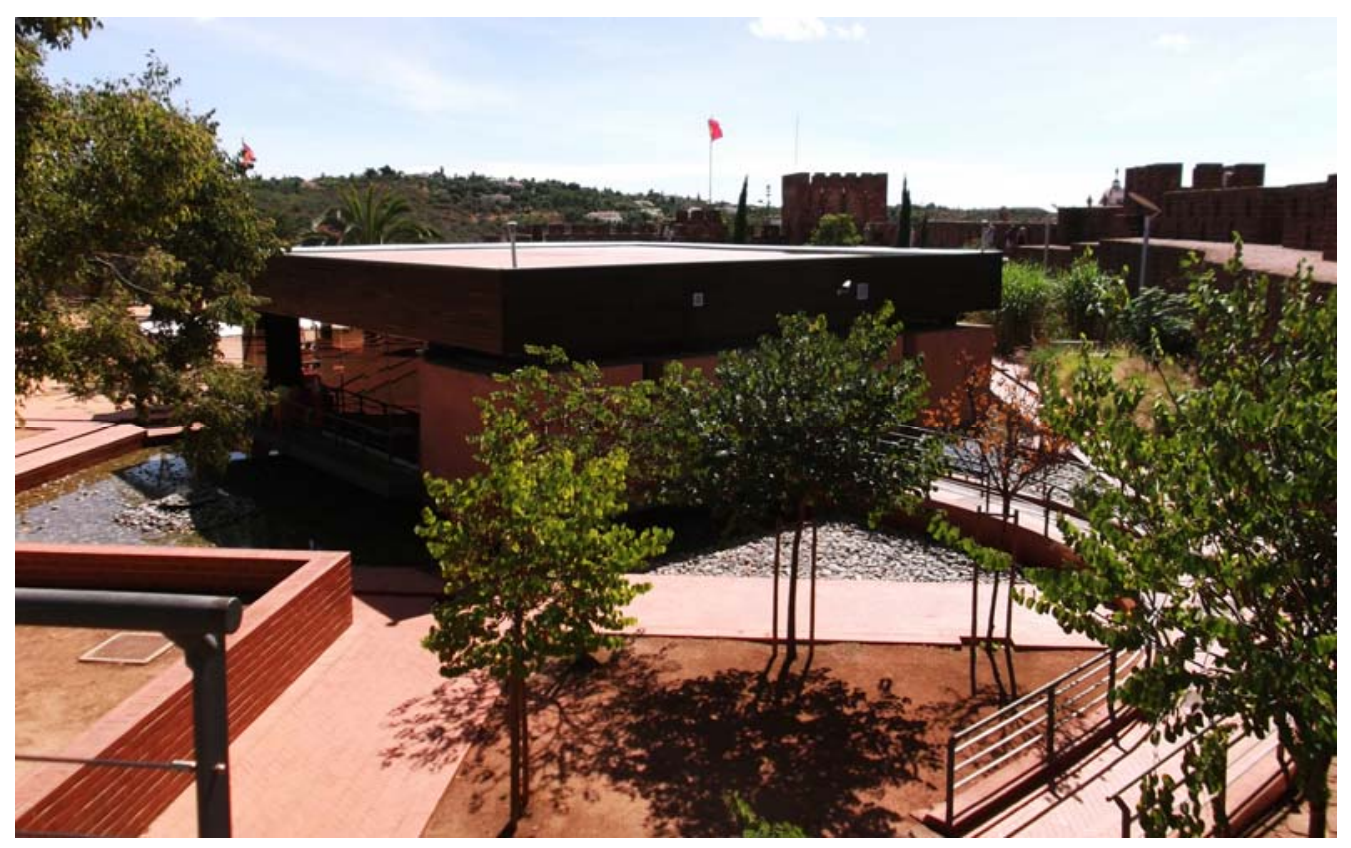

Figura 3. Castelo de Silves: casa de chá resultante da intervenção patrimonial. Silves, distrito de Faro, região do Algarve, 2013. Fotografia da autora. 
As intervenções foram analisadas sob o ponto de vista das abordagens que têm surgido recentemente no que diz respeito ao conceito de património e gestão dos lugares patrimoniais. Estas abordagens identificam alguns problemas que têm surgido relativamente à expectativa económica que se colocou no património como factor de desenvolvimento e o afastamento das comunidades no processo de decisão ou mesmo na gestão dos lugares patrimoniais, o que pode significar que a intervenção patrimonial não é desenvolvida segundo as especificidades de cada contexto. Foram então tidos em consideração factores como a expectativa económica presente no conceito ou na estratégia da intervenção, a intervenção como mero exercício de arquitectura, os valores que a comunidade associa ao castelo, a sua participação no processo de decisão, as características socioeconómicas de cada contexto, a promoção do castelo pelas entidades locais, entre outros factores, utilizando-se variadas técnicas de recolha de informação.

Neste sentido, pretendeu-se delinear perspectivas que possibilitem uma resposta aos problemas que se verificaram nos estudos de caso de acordo com os recursos e singularidades locais. Seguidamente apresentam-se as principais ideias resultantes do presente estudo.

As intervenções apresentam um progressivo abandono de critérios de intervenção dogmáticos ou restritos a uma interpretação rigorosa das Recomendações existentes, sendo que a adaptação à fruição pública na expectativa de atrair visitantes é notória e praticamente transversal a todas as intervenções. Verificou-se que a mensagem construída para ser interpretada continua a basear-se em informação factual no sentido dos valores históricoartísticos, ou seja, no sentido tradicional do que significava autenticidade. A pouca diferenciação existente nesta questão leva a perspectivar que o público é entendido como uma audiência difusa e de massas, onde é suposto que tenha interesse na apreensão de uma mensagem baseada em factos históricosartísticos. Existe, portanto, uma clara distinção entre a forma como a interpretação é efectuada nos castelos analisados e a nova perspectiva sobre o que poderá entender-se actualmente como autenticidade. Se se considerar que o património não se caracteriza pelo seu valor intrínseco mas naquilo que significa para a construção de uma identidade individual ou colectiva, as técnicas utilizadas nos castelos analisados poderão deixar de ser efectivas no seu propósito, sendo que a interpretação poderá ter uma outra leitura: sendo media- 
dora da mensagem entre cada uma das gerações e não tanto a construção de uma mensagem para um público indefinido.

Esta questão tem implicações directas na forma como é entendido o castelo, ou a estrutura pré-existente, o que se reflecte nas intervenções patrimoniais. Verificou-se que existe pouca diferenciação neste sentido: o castelo é entendido com uma estrutura na qual se intervém segundo um projecto de arquitectura e por isso constitui uma acção pontual, ignorando-se todos os aspectos que relacionam o castelo com o território e o imaginário popular.

Neste sentido assistiu-se, nas intervenções analisadas, a uma musealização da estrutura pré-existente e uma intervenção restrita a essa mesma estrutura. Se existe uma contínua musealização significa que existe da mesma forma um gradual afastamento do castelo relativamente às especificidades do contexto onde se insere, reflectindo-se na pouca adequabilidade das intervenções no que toca ao desenvolvimento local e valorização do castelo de acordo com o significado que o mesmo pode ter para a comunidade local.

Relativamente à expectativa económica verificou-se a intervenção teve pouco ou nenhum impacto, mesmo que a intervenção possa ter gerado maior afluência de visitantes. Sendo assim, essa expectativa na atracção de visitantes, sem outras estratégias, poderá não significar geração de riqueza, pelo que se deve questionar a continuada justificação das intervenções para uma valorização do castelo e consequente afluência de visitas.

Deve salientar-se que uma intervenção pontual, por mais bem conseguida que seja em termos arquitectónicos e gerando uma maior afluência de visitantes, não constitui por si só factor de desenvolvimento, é necessário um contínuo trabalho entre diferentes agentes e em outras áreas além dos bens patrimoniais classificados. Nas intervenções analisadas existem contextos socioeconómicos muito diferentes entre si. Por exemplo, o caso de Amieira do Tejo apresenta uma acentuada desertificação, sem recursos que potencializem a revitalização da localidade, pelo que o castelo, na óptica dessa expectativa económica que está associada ao património, se assume como um dos principais factores que poderá contribuir para essa revitalização. No entanto, essa estratégia terá necessariamente de ser englobada em outras acções para que haja um efectivo desenvolvimento local e de forma continuada, pelo que constitui um caso onde existe alguma ponderação e abertura para uma estratégia diferente no que toca 
às questões do desenvolvimento económico. Um caso bastante diferente é o caso de Silves, em que a afluência de visitantes ao castelo é muito significativa durante todo o ano, e existe algum impacto no comércio local devido a essa afluência, o que torna a intervenção menos sujeita a essa expectativa económica visto que a estrutura pré-existente não necessita de uma grande intervenção para a sua valorização. No entanto, esse impacto ainda não é o desejável pois muitas vezes os visitantes apenas permanecem na cidade o tempo que demora a visita ao castelo, não havendo um efectivo benefício para o comércio local na sua generalidade. Após estes dois exemplos verifica-se que um profundo conhecimento do contexto socioeconómico é fulcral para delinear acções que justifiquem uma intervenção patrimonial.

Relativamente aos vários significados associados ao castelo por parte da comunidade existem valores de diversas ordens, como por exemplo em termos iconográficos, históricos, do imaginário popular, valor pessoal pelo facto de ter sido importante na construção de uma identidade individual ou mesmo a não valorização. Através desta análise torna-se evidente que os valores atribuídos ao castelo vão muito para além daqueles em que a construção da mensagem se baseia para a interpretação por parte do público. Por exemplo, no caso de Celorico da Beira, a intervenção veio reforçar a valorização do castelo para os habitantes, sendo que a mesma constitui também esse mesmo reforço nos habitantes que não valorizavam o castelo, passando a ser a própria intervenção um marco na valorização do castelo e por isso provavelmente irá contribuir para a construção de uma identidade individual ou colectiva. No caso de Amieira do Tejo, denota-se um desinteresse significativo da comunidade pela intervenção ou a não participação nas actividades promovidas pela mesma. Esta questão poderá ser um reflexo de que os habitantes não atribuem os mesmos valores ao castelo que a comunidade científica.

No entanto, no castelo de Amieira do Tejo existem diversas actividades, como por exemplo a festividade religiosa anual da localidade, e em que a procissão desse acto religioso acontece no interior do castelo, existindo uma efectiva participação da comunidade local nessas actividades. Outro caso é o castelo de Trancoso, onde existiu um teatro intramuros, e por isso havia uma grande dinamização do espaço para a comunidade local, sendo aliás referência nas monografias sobre a história local, constituindo um marco na memória colectiva da localidade. 
Embora possam existir usos mais adequados, com estes casos apenas se pretende ilustrar a importância de incluir na intervenção patrimonial um estudo sobre o significado do castelo para a comunidade, que poderá resultar inclusivamente apenas na adaptação do castelo para a fruição pública, como aconteceu no caso de Celorico da Beira. É necessário referir que quando existe, relativamente a um determinado monumento ou lugar, uma valorização da comunidade local, isto poderá ter impacto relativamente à sustentabilidade da manutenção.

Desta forma, as novas abordagens ao conceito de património como um processo de construção de identidade(s) não foram um ponto de partida nas intervenções analisadas, pelo que as mesmas continuam a pautar-se por intervenções pontuais e restritas à criação de condições para a fruição pública ou esporadicamente para um uso cultural. Tal facto é claro pela quase inexistência de uma participação cívica no processo de decisão e em alguns casos, como o caso de Silves, a falta de cooperação com as entidades locais, mesmo que sejam da esfera especialista, no processo de decisão. No caso de Portalegre há uma tentativa de que a intervenção se torne útil para o centro histórico, promovendo espaços que sejam utilizados pela comunidade local. No entanto verifica-se que esta intenção não teve o efeito esperado, sendo que um dos factores poderá ser a falta de adequabilidade às características da comunidade que habita o próprio centro histórico.

Quando se questiona a importância de uma participação cívica, denota-se que não existe, por parte das comunidades, uma ideia clara em que é que essa acção se traduz. Isto poderá significar algumas dificuldades se se perspectivar futuramente uma nova abordagem à intervenção patrimonial relativamente a esta questão, sendo que coloca desafios muito pertinentes.

\section{Notas conclusivas.}

Para permitir uma sustentabilidade dos castelos face a desafios anteriormente indicados, a intervenção patrimonial nos castelos portugueses poderá ter de deixar de constituir uma intervenção arquitectónica pontual baseada na estrutura pré-existente. Deverá, pelo contrário, constituir um processo multidisciplinar que vise uma mediação entre os valores associados aos castelos e os valores históricoartísticos, numa perspectiva de criar formas de gestão que permitam um compromisso entre gerações e dessa forma uma manutenção eficaz a médio e longo 
prazo, traduzindo-se num processo contínuo no trabalho com as comunidades. Esta questão é fulcral no processo de intervenção pois é necessário entender aquilo que se torna identitário para uma determinada geração e com que acções se podem promover uma continuação desses valores. Assim, a interpretação passa a ser entendida numa outra óptica, deixando de constituir a construção de uma série de técnicas para a apresentação de uma determinada mensagem baseada em factos científicos dirigida a uma audiência de massas. Se se considerar, pelo contrário, devido à multiplicidade de significados de património, que cada um dos visitantes apreende uma mensagem de uma forma singular, este factor pode até promover um diálogo entre a comunidade local e os visitantes na apreensão de alguns factos históricos, ou de outra ordem, que possam interessar aos visitantes e promover a aquisição de conhecimento sobre a localidade que se visita. A intervenção patrimonial deverá assim resultar de um profundo conhecimento das características e potencialidades locais e de uma resposta efectiva a essas mesmas particularidades, para que o património constitua um factor de desenvolvimento local.

A compreensão dos valores que as comunidades locais associam ao castelo e o seu contexto territorial devem ser um ponto de partida, pois só com uma valorização do castelo é que as comunidades locais poderão contribuir activamente para a manutenção, divulgação e conservação, podendo existir outros usos, que embora não sejam previstos pelos especialistas, sirvam o contexto local para além da adaptação dos castelos à fruição pública.

Este processo, para se tornar operativo, constitui assim uma nova problemática que necessita de estudos com maior profundidade e de um desenvolvimento de metodologias que permitam a sua aplicação. Sendo que este processo se antevê complexo, sobretudo por se basear nas especificidades de um determinado contexto, e portanto não dogmático, sendo que os resultados variam de caso para caso, coloca não só novos desafios ao arquitecto, nomeadamente à sensibilidade, responsabilidade e profundo conhecimento relativamente às questões do património, mas também à formação académica. Deverá também haver uma maior disponibilização de acções de formação tanto a nível nacional como internacional, com uma forte componente prática, onde seja possível adquirir tais valências para permitir que seja possível antever uma nova abordagem nas intervenções patrimoniais nos castelos, e que poderão igualmente ser aplicadas a outros lugares ou bens patrimoniais. 
Por fim, existe uma questão que é pouca abordada especificamente no contexto português relativamente aos castelos, e que remete para a crise de acumulação.

Os castelos em Portugal, dada a sua grande quantidade e inexistência de função militar desde há vários séculos, constituem um caso singular na abordagem e essa mesma crise de acumulação. Os castelos estão na sua maioria classificados, chegando quase às duas centenas, embora não se tenha encontrado referências exactas quanto ao número de castelos classificados até ao momento. Têm uma importância iconográfica na paisagem portuguesa, onde alguns castelos, pela importância estratégica, desenvolveram uma povoação e se tornaram duplamente importantes não só na leitura do território mas também na memória colectiva, quando assim se constituem. No entanto, existem alguns castelos que se encontram já com muito poucos vestígios, principalmente aqueles que tiveram uma função estratégica secundária e não desenvolveram povoação. Isto poderá ser reflexo de que estes castelos, ou contrário de outros, não tomaram parte no processo de criação de identidade(s). Neste sentido deverá questionar-se se se deverá manter ou não a sua preservação face aos problemas gerados pela crise de acumulação de bens patrimoniais classificados, tendo em consideração o significado desses castelos para as comunidades na envolvente e no enquadramento do território ao qual pertencem.

\section{Bibliografia}

AgUiAR, J. (2010): “Após Veneza: do restauro estilístico para o restauro científico", em CUSTÓDIO, J. (coord.). 100 de património: memória e identidade. IGESPAR, Lisboa, pp. 219-235.

AltenburG, K. (2010): “Heritage 2010”, em AMOÊDA, R., LiRA S. \& PINHEIRO C. (eds.). Heritage 2010: heritage and sustainable development. Greenlines, Évora, Vol. 1, pp. 11-18.

ANDRADE, A. (2001): A construção medieval do território. Livros Horizonte. Lisboa.

AsHWORTH, G. (1995): “Heritage, Tourism and Europe: a European future for a european past?", em HeRBERT D. (ed.). Heritage, Tourism and Society. Pinter, Londres, pp. 117-145.

AUGÉ, M. (2005): Não- lugares: Introdução a uma antropologia da Sobremodernidade. $90^{\circ}$. Lisboa.

BARROS, M. (2007): Tempos e espaços de mouros: a minoria muçulmana no reino português (séculos XII a XV). Fundação Calouste Gulbenkian. Lisboa. 
BELYAEV, D. (2010): "Local heritage as a development asset? The case of the island Hvar in Croatia", em AMOÊDA, R., LIRA S. \& PINHEIRO C. (eds.). Heritage 2010: heritage and sustainable development. Greenlines, Évora, Vol. 1, pp. 19-27.

CARDONA, P. (2009): "Património e turismo", em DIAS, F., SOIFER J. \& FERREIRA L. (eds.). O futuro do turismo: território, património, planeamento. Estratégias criativas, Vila Nova de Gaia, pp. 33-50.

CHOAY, F. (2006): A alegoria do Património. Edições 70. Lisboa.

CHOAY, F. (2011): As questões do património: antologia para um combate. Edições 70, Lisboa.

CUSTÓDIO, J. (2010) “Globalização e património cultural”, em Custódio J. (coord.) 100 anos de património: memória e identidade. IGESPAR, Lisboa, pp.346-348.

DUARTE, A. (2010): “The contemporary way to protecting heritage or, the only way for heritage to serve the development of communities", em AMOÊDA, R., LIRA S. \& PINHEIRO C. (eds.). Heritage 2010: heritage and sustainable development. Greenlines, Évora, Vol. 1, pp. 855-864.

FOLGADO, D. (2010): "Património inclusivo. Das expectativas aos desafios", em CUSTÓDIO J. (coord.). 100 anos de património: memória e identidade. IGESPAR, Lisboa, pp. 323-335.

HARRISON, R. (2013): Heritage: critical approaches. Routledge. Oxon.

Herbert, D. (1997): “Heritage Places, Leisure and Tourism”, em Herbert D. (ed.). Heritage, Tourism and Society. Pinter, Londres, pp. 1-20.

JOKILEHTO, J. (2004): A History of Architectural Conservation. Elsevier. Oxford.

LiGHT, D. (1997): "Heritage as informal education", in HERBERT D. (ed.). Heritage, Tourism and Society. Pinter, Londres, pp. 117-145.

NUNES, A. (1988): O castelo estratégico português e a estratégia do castelo em Portugal. Direcção do Serviço Histórico Militar. Lisboa.

RibeIRO, O. (1998): Portugal, o Mediterrâneo e o Atlântico: esboço de relações geográficas. Livraria Sá e Costa. Lisboa.

SCHOUten, F. (1997): “Heritage as Historical Reality”, em HERBERT D. (ed.). Heritage, Tourism and Society. Pinter, Londres, pp. 21-31.

SMITH, L. (2006): Uses of heritage. Routledge. Oxon.

SOIFER, J. (2009): "Beating an economic crisis with tourism", em DIAS, F., SOIFER J. \& FERREIRA L. (eds.). O futuro do turismo: território, património, planeamento. Estratégias criativas, Vila Nova de Gaia, pp. 123-135. 
STEVENS, T. (1997): "Heritage as Design: a practitioner's perspective”, em HERBERT D. (ed.). Heritage, Tourism and Society. Pinter, Londres, pp. 191-211.

YIN, R. (2003): Case Study Research-Design and Methods. Sage Publication. California

\section{Recursos web.}

BLAKE, J. (2002): Developing a New Standard-setting Instrument for the Safeguarding of Intangible Heritage: Elements for consideration. Acedido em 8 de Outubro de 2013, em http://unesdoc.unesco.org/images/0012/001237/ 123744e.pdf

CASTElls, M. (2010): The power od identity. Wiley-Blackwell. Oxford, Vol II. Acedido 6 de Outubro, 2013, em http://gendocs.ru/docs/10/9373/conv_1 /file1.pdf

KIDD, J. (2011): "Performing the knowing archive: heritage performance and authenticity". International Journal of Heritage Studies. 17, pp. 22-35. Acedido 05/09/2013, http://www.tandfonline.com/doi/pdf/10.1080/13527258.2011.524003

MARQUES, J. (1988): Povoamento e defesa na estruturação do Estado português. Acedido 18/01/2014, em http://ler.letras.up.pt/uploads/ficheiros/6441.pdf

MunJERI, D. (2004): “Tangible and Intangible Heritage: from diference to converge". Museum, 56, pp. 221-222. Acedido em 23 de Outubro de 2013, em http://onlinelibrary.wiley.com/doi/10.1111/j.1350-0775.2004.00453.x/pdf

SANTOS, J. (2012a): “A castelologia portuguesa e a evolução dos estudos sobre fortificações medievais em Portugal”. Portvgalia, 33, pp. 107-143. Acedido em 05/02/2014, em http://ler.letras.up.pt/uploads/ficheiros/10815.pdf.

SANTOS, J. (2012b): Anamnesis del castillo como bien patrimonial: Construcción de la imagen, forma y (re)funcionalización en la rehabilitación de fortificaciones medievales en Portugal (Tese de doutoramento não publicada). Universidade de Alcalá, Espanha. Acedido em 8 de Outubro de 2013, em http://dspace.uah.es/dspace/handle/10017/14021. 